This item was submitted to Loughborough's Research Repository by the author.

Items in Figshare are protected by copyright, with all rights reserved, unless otherwise indicated.

\title{
Disentangling within-person changes and individual differences among fundamental need satisfaction, attainment of acquisitive desires, and psychological health
}

\section{PLEASE CITE THE PUBLISHED VERSION}

http://dx.doi.org/10.1016/j.jrp.2012.06.002

\section{PUBLISHER}

(C) Elsevier

VERSION

AM (Accepted Manuscript)

\section{LICENCE}

CC BY-NC-ND 4.0

\section{REPOSITORY RECORD}

Taylor, lan M., and Juliette Stebbings. 2019. "Disentangling Within-person Changes and Individual Differences Among Fundamental Need Satisfaction, Attainment of Acquisitive Desires, and Psychological Health". figshare. https://hdl.handle.net/2134/10617. 
This item was submitted to Loughborough's Institutional Repository (https://dspace.lboro.ac.uk/) by the author and is made available under the following Creative Commons Licence conditions.

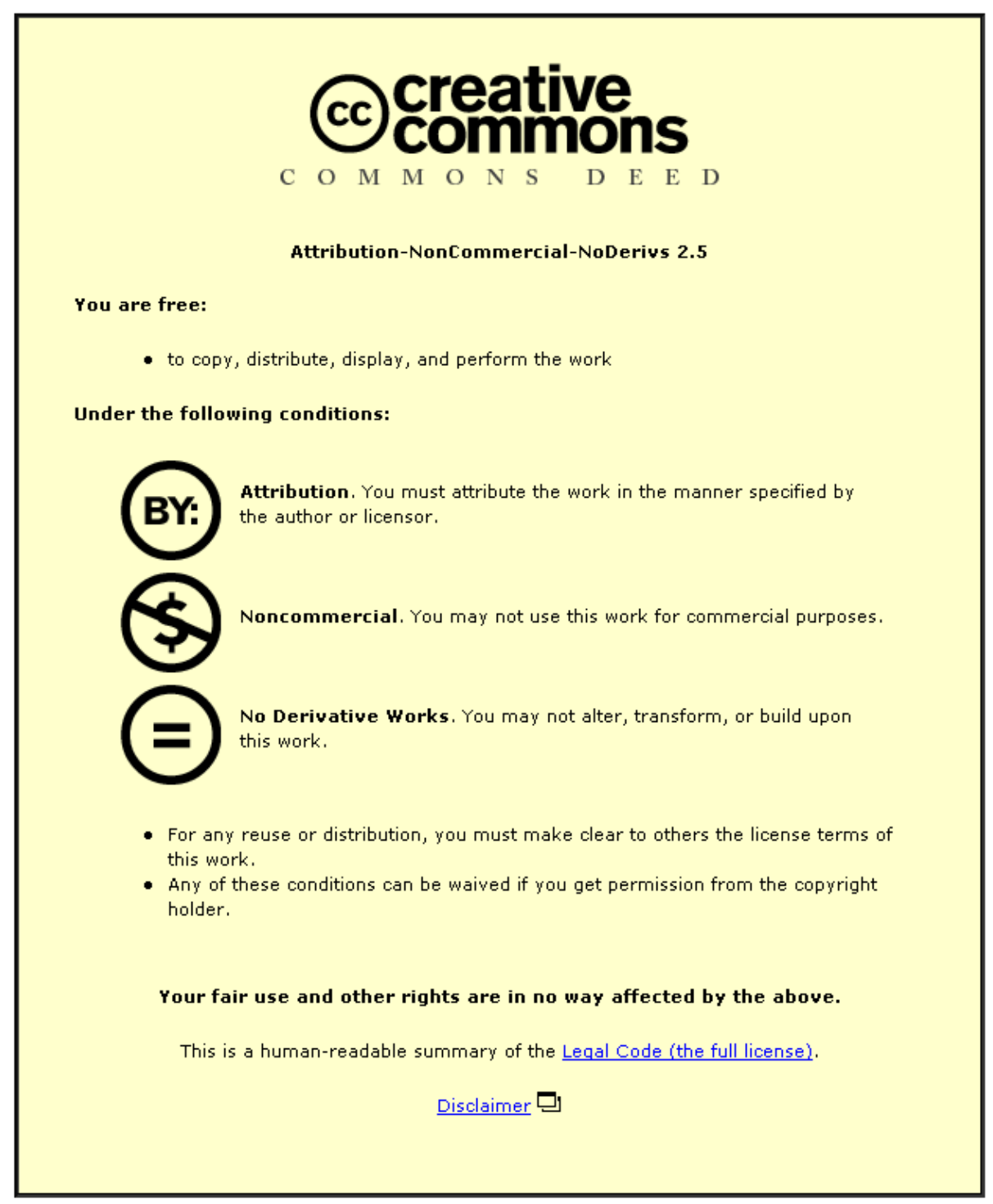

For the full text of this licence, please go to: http://creativecommons.org/licenses/by-nc-nd/2.5/ 
7 Disentangling within-person changes and individual differences among fundamental need satisfaction, attainment of acquisitive desires, and psychological health

9

10

11

12

13

14

15

16

18

19

20

21

22

23

17

Manuscript submitted: January, $12^{\text {th }}, 2012$

Manuscript resubmitted: May 24 $4^{\text {th }}, 2012$

Word count: 2940

\section{4}

15

18

9

0




\section{Abstract}

25 We explored within-person and individual difference associations among basic psychological need

26 satisfaction (autonomy, competence, and relatedness), attainment of acquisitive desires (wealth and

27 popularity) and indicators of well- and ill-being. Participants were 198 undergraduates (51\% male)

28 who completed an inventory multiple times over a university semester. Analyses revealed that

29 increased satisfaction of all the needs and desires beyond participants' normal levels, with the

30 exception of relatedness, were associated with greater psychological welfare. Nonetheless,

31 individual differences in well-being were only predicted by psychological need satisfaction, and not

32 by the attainment of acquisitive desires. Hence, the realization of acquisitive desires may elicit

33 within-person increases in psychological welfare; however, satisfying innate needs may be a better

34 bet for long term psychological health.

36 Keywords: Money, social recognition, psychological needs, well-being, self-determination 
Disentangling within-person changes and individual differences among fundamental need satisfaction, attainment of acquisitive desires, and psychological health

\section{Introduction}

Whether gratification of one's desires for riches and status leads to psychological well-being

50 or satisfaction of other fundamental psychological needs plays a more significant role has been

51 widely debated in the literature (e.g., Sheldon, Elliot, Kim, \& Kasser, 2001). The early work of

52 Murray (1938) implied that any motive that drives action and is associated with satisfying

53 experiences when met may be considered a need. Contrastingly, supporters of self-determination

54 theory (SDT) advocate that humans are innately driven to pursue autonomy, competence, and

55 relatedness, and only the satisfaction of these psychological nutrients are essential to experience well-

56 being (e.g., Vansteenkiste, Niemiec, \& Soenens, 2010). We wished to extend current knowledge by

57 extricating individual differences and within-person changes among need satisfaction, attainment of

58 desires, and psychological health to help elucidate differences between fundamental needs and

59 acquisitive desires.

60 A fundamental psychological need must meet several criteria, including the elicitation of

61 positive consequences when met, as well as ill effects when thwarted (Baumeister \& Leary, 1995).

62 Satisfying the desire for wealth may have evolutionary benefits for one's health and, therefore, may

63 represent a psychological need (e.g., Kanazawa, 2003). Similarly, popularity has been discussed as a

64 human need by socio-analytical psychologists, who propose that individuals are motivated to

65 accumulate status so one can psychologically thrive (e.g., Hogan, 1996). Alternatively, evidence

66 exists that suggests the satisfaction of the yearning to be wealthy and popular is unconnected to

67 psychological health (e.g., Niemiec, Ryan, \& Deci, 2009), irrespective of the value placed on 
68 fulfilling these goals (Vansteenkiste et al., 2010). These longings are, therefore, merely desires, rather

69 than needs.

70 Rather than focusing on satisfying one's desire for social status and material prosperity, self-

71 determination theorists (e.g., Vansteenkiste et al., 2010) advocate that humans are inherently driven to

72 pursue competence (effectiveness within one's environment), relatedness (engagement in meaningful

73 social relationships), and autonomy (self-initiation of one's behavior). Using SDT as a framework,

74 studies have shown that the fulfilment of autonomy, competence, and relatedness is positively

75 associated with well-being and negatively related to ill-being (e.g., Reis, Sheldon, Gable, Roscoe, \&

76 Ryan, 2000). This research also suggests that the relations among the three needs and indicators of

77 well- and ill-being may differ according to the exploration of within-person changes or individual

78 differences. However, a comparison between fulfilment of specific psychological needs advocated by

79 self-determination theorists and acquisitive desires was not conducted and is, therefore, the focus of

80 the present study.

81 We aimed to fill this gap by exploring the extent to which satisfaction of five needs and

82 desires (i.e., autonomy, competence, relatedness, wealth, and popularity,) predicted various indicators

83 of well- (i.e., positive affect and vitality) and ill-being (i.e., negative affect, sleep disturbance, and

84 frequency of headaches). Regarding popularity, we replicated Sheldon and colleagues' (2001)

85 attempts to stay faithful to the 'American dream' lay perspective of popularity; although we

86 acknowledge that this may have some conceptual overlap with individuals' influence over others.

87 Sheldon et al. found consistently found stronger relationships among the three SDT-advocated needs

88 and affect, compared to wealth and popularity. The present study attempted to build on this work by

89 examining the study variables over a three-month time period, which allowed us to explore whether

90 a) individual differences in the satisfaction of the needs and desires were associated with well- and ill- 
91 being, and b) within-person fluctuations were related to well- and ill-being. This disentanglement is

92 significant because the two levels of relationships are conceptually and statistically distinct. Fulfilling

93 a desire may be associated with positive consequences at the within-person level but not individual

94 differences in well-being. Satisfaction of a need may also be related to within-person changes in well-

95 being, however, individuals whose needs are met should also report greater levels of well-being,

96 compared to individuals whose needs are not met (Vansteenkiste et al., 2010). In other words, it is the

97 satisfaction of fundamental needs, and not acquisitive desires, which separate those individuals who

98 are psychologically thriving from those who are not.

99 We aligned with SDT by suggesting that autonomy, competence, and relatedness are

100 fundamental to human thriving and represent a psychological need, whereas, wealth and popularity

101 are psychological desires which are not fundamental to optimal functioning. As such, we

102 hypothesized that satisfaction of all five needs and desires would be related to positive consequences

103 (i.e., higher positive affect and subjective vitality, and lower negative affect) at the within-person

104 level. In contrast, only individual differences in the satisfaction of three SDT-based needs would be

105 related to positive psychological consequences. No individual difference relationships were expected

106 among satisfaction of the desires for popularity and wealth and psychological consequences.

107 Our hypotheses were less clear with regard to physical symptoms of ill-being (i.e., sleep

108 disturbance and frequency of headaches), given that previous research has offered mixed support for

109 the relationship between psychological need satisfaction, in particular relatedness, and poor somatic

110 health (e.g., Reis et al., 2000). Therefore, we proposed that at both levels of analysis low satisfaction

111 of autonomy and competence would be related to increased somatic symptoms of ill-health, whereas

112 unsatisfied desires (i.e., wealth and popularity) and relatedness would not. 


\section{2.1. Participants and Procedure}

115 Participants were 198 undergraduates aged between 19 and 30 years $(M=19.82, S D=$

$1161.47,51 \%$ male) who were based in England. Forty students completed the inventory four times,

11781 completed it three times, 54 completed it twice, and 23 completed it once. Following ethical

118 procedures, participants completed an inventory containing all study variables during the second,

119 third, fifth, eighth, and tenth week of a university semester (some participants were given the

120 questionnaire in different weeks).

\section{2.2. Measures}

122 2.2.1. Attainment of Psychological Needs and Desires was measured by asking

123 participants to respond to the stem "during the past week, I felt" followed by 15 items (three

124 items for each need or desire) previously used and validated by Sheldon et al. (2001). All items

125 were responded to on a 5-point scale ranging from 1 (not at all) to 5 (very much).

126 2.2.2. Vitality was measured using the validated seven item version of the Subjective

127 Vitality Scale (Ryan \& Frederick, 1997). Participants read the stem "during the past week"

128 followed by the items and responded using a 7-point scale, anchored by 1 (not at all true) and 7

129 (very true).

130 2.2.3. Positive and Negative Affect was assessed using the previously validated Positive

131 And Negative Affect Scale (Watson, Clark, \& Tellegen, 1988). Participants were asked to rate

132 how much they have experienced ten positive and ten negative emotions during the past week on

133 a 5-point scale ranging from 1 (very slightly or not at all) to 5 (extremely).

$134 \quad 2.2 .4$. Sleep Disturbance and Frequency of Headaches were measured using the four

135 and three items that comprise the respective subscales of the Physical Health Questionnaire 
136 (PHQ; Schat, Kelloway, \& Desmarais, 2005). Participants were asked to consider the last week

137 and respond using a scale ranging from 1 (not at all) to 7 (all the time).

\section{Results}

All subscales demonstrated adequate internal consistency $(\alpha \geq .60)$ and correlations

140 between the study variables suggested that multicollinearity was not an issue (specific details can

141 be obtained upon request from the first author).

142 Using MLwin 2.10 software (Rasbash, Steele, Browne, \& Goldstein, 2009), we estimated

143 level 1 (i.e., within-person) and level 2 (i.e., individual differences) relationships simultaneously.

144 All predictor variables were explored as random effects; however, they were entered as fixed

145 effects in the models if the level 2 slope variance was not significant or the deviance scores did

146 not indicate better model fit. To examine within-person relations the five psychological needs and

147 desires were group mean centred and entered as predictors in the level 1 equation of the

148 respective models. To examine individual difference relationships, participants' mean scores of

149 the five needs and desires were centered on the sample mean across all time points and entered

150 into the level 2 equation. To further investigate potential differences between individual

151 differences in need and desire attainment, we also constructed a series of models in which the

152 slope of one psychological need was constrained to be equal with the slope of one desire. If these

153 models showed worse fit to the data than an unconstrained model the respective slopes (i.e.,

154 relationships) were assumed to be different. Results can be seen in Table 1 and are summarized

155 for each outcome variable below.

156 3.2.1. Vitality. Increases in attainment of all the needs and desires beyond one's normal

157 levels were associated with greater vitality, with the exception of relatedness. Moreover,

158 participants who had their needs for competence, autonomy, and relatedness satisfied generally 
159 reported higher vitality, compared to participants who did not have these needs satisfied. No

160 individual difference relationships were found for wealth and popularity. Comparison of

161 constrained and unconstrained models revealed that significant differences existed between the

162 level 2 slope coefficients of the needs and the desires (range of $\Delta \chi^{2}=4.12-11.14, d f=1$, all $p<$

163 .05), with the exception of relatedness and money $\left(\Delta \chi^{2}=3.06, d f=1, p>.05\right)$.

164 3.2.2. Positive affect. Increases in attainment of competence, autonomy, and popularity

165 beyond one's normal levels were related to higher positive affect. The relationship between

166 competence and positive affect significantly varied across participants. In addition, participants

167 who had their needs for competence, autonomy, and relatedness satisfied generally reported

168 greater positive affect, compared to participants who did not have these needs satisfied. No

169 individual difference relationships were found for wealth and popularity. Comparison of

170 constrained and unconstrained models revealed that significant differences existed between the

171 level 2 slope coefficients of the needs and the desires (range of $\Delta \chi^{2}=4.93-10.36, d f=1$, all $p<$

$172.05)$, with the exception of relatedness and popularity $\left(\Delta \chi^{2}=2.08, d f=1, p>.05\right)$.

173 3.2.3. Negative affect. Increases in attainment of the desires or needs were not associated

174 with negative affect, however, the relationships among increases in competence, relatedness and

175 negative affect varied significantly across participants. Further, participants who had their needs

176 for competence and autonomy satisfied generally reported feeling less negative affect, compared

177 to participants who did not have these needs satisfied. No individual difference effects were

178 found for relatedness, wealth, and popularity (however, the relationship between popularity and

179 negative affect varied across participants). Comparison of constrained and unconstrained models

180 revealed that significant differences existed between the level 2 slope coefficients of the two

181 significantly related needs (i.e., autonomy and competence. Relatedness was not tested as it did 
182 not significantly predict negative affect) and the desires (range of $\Delta \chi^{2}=8.11-16.14, d f=1$, all $p$ $183<.05)$.

184 3.2.4. Sleep disturbance. Increases in attainment of competence and wealth above one's

185 normal levels were associated with less sleep disturbance. However, there were no significant

186 relationships between individual differences in the attainment of needs and desires and sleep

187 disturbance.

188 3.2.5. Headaches. Increases in attainment of the desires or needs were not associated with

189 frequency of headaches, however, the relationship between increases in popularity and headache

190 occurrence significantly varied across participants. Again, there were no significant relationships

191 between individual differences in the needs and desires and headache occurrence.

\section{Discussion}

Findings within the present study suggested that increased attainment beyond one's

194 normal levels in two of the three psychological needs advocated by SDT (i.e., autonomy and

195 competence), as well as popularity and wealth are associated with positive affective responses

196 and vitalized functioning. However, differences between SDT-based needs and acquisitive

197 desires were found at the individual difference level. Participants who satisfied their desire to be

198 wealthy and popular did not report enhanced well-being, compared to participants who were

199 unsatisfied. Contrastingly, individuals who felt autonomous, competent, and related reported

200 greater psychological health, compared to individuals with lower levels of psychological need

201 satisfaction. Results were less conclusive regarding indicators of ill-being.

202 Our results imply that an individual who experiences an increase in his or her

203 satisfaction of competence (e.g., feeling proficient at work after a successful project), autonomy

204 (e.g., having more time to participate in activities of one's choosing than normal), popularity 
205 (e.g., a sudden increase in attention on social networking websites), and wealth (e.g., an

206 unexpected pay rise) is likely to function with more energy and vitality during these changes.

207 Further, greater feelings of competence, autonomy, and popularity compared to usual are likely to

208 be associated with higher positive affect. The immediate positive correlates associated with

209 elevated attainment of popularity and wealth may explain why these two desires are so sought

210 after (Bandura and Locke, 2003). Similarly, the proposition that increased agency and

211 effectiveness will correspond with energized functioning and increased positive affect has robust

212 support. In contrast to Reis et al. (2000), however, we did not find any significant relationships

213 between increases in the satisfaction of relatedness beyond one's normal levels and positive affect

214 or vitality. These equivocal findings imply that in certain contexts, fluctuations in relatedness

215 satisfaction may play a lesser role in healthy psychological functioning, compared to autonomy

216 and competence. As we discuss later, however, this isolation should not become the typical

217 experience for any given individual.

218 Limited support was established for our proposal that decreases in the satisfaction of

219 the psychological needs and acquisitive desires beyond one's normal levels would lead to higher

220 reported ill-being. Decreased feelings of competence and attainment of wealth compared to

221 normal were associated with disturbed sleep. Financial concerns have been shown to be a

222 significant potential stressor in undergraduate samples (Ross, Cleland, \& MacLeod, 2006), which

223 may explain why a participant would experience troubled sleep if he or she does not feel as

224 financially satisfied as normal. Generally speaking, fluctuations in the SDT-based psychological

225 needs did not impact upon individuals' ill-being. We based this hypothesis on Deci and Ryan's

226 (2000) proposal that thwarting individuals' psychological needs will result in diminished

227 functioning, as well as work proposing more specific links (e.g., social isolation and reduced 
228 sleep quality; Hawkley, Preacher, \& Cacioppo, 2011). However, research has often found similar

229 non-significant relationships among psychological need satisfaction and indicators of ill-being

230 (e.g., Reis et al., 2000). Recent work by Bartholomew, Ntoumanis, Ryan, Bosch, \& Thørgesen-

231 Ntoumani (2011) proposed that a lack of need satisfaction (i.e., what we measured in the present

232 study) is conceptually distinct from overt thwarting of psychological needs and this distinction

233 may explain why non-significant relationships between psychological need satisfaction and

234 maladaptive consequences are often found.

As expected, a clear distinction can be seen between psychological needs and desires

236 when examining individual differences in the fulfilment of these constructs and their associations

237 with well-being. Individuals who reported high satisfaction of the desire for wealth and

238 popularity did not report higher psychological well-being, compared to individuals who reported

239 low satisfaction. In contrast, participants whose psychological needs for autonomy, competence,

240 and relatedness are generally fulfilled in life reported greater psychological well-being, compared

241 to individuals who experience less psychological need gratification. These results were

242 supplemented by the finding that participants who reported lower autonomy and competence

243 satisfaction reported higher negative affect, compared to participants who reported greater felt

244 autonomy and competence. Thus, our results suggest that individuals who feel a sense of self-

245 initiation and effectiveness in their activities, as well as a connectedness with important others are

246 likely to experience a fulfilling life. Those individuals who gratify their need for status and riches

247 may not be guaranteed such a positive existence, despite some immediate benefits of attaining

248 social recognition and wealth beyond one's normal levels.

It is worth noting that, in some instances, the relationships associated with relatedness

250 need satisfaction were not found to be different than those of wealth and popularity attainment. 
251 Even so, although increases in participants' sense of relatedness satisfaction beyond one's normal

252 levels did not correspond to enhanced levels of well-being, individuals who were generally higher

253 in feelings of relatedness satisfaction reported more vitality and positive affect than their

254 unrelated counterparts. Thus, it seems that chronic satisfaction of relatedness has a key role in

255 psychological well-being, but fluctuations in relatedness may not be so impactful.

\section{4.1. Limitations, Future Directions and Conclusions}

Despite providing a detailed picture of the varying consequences of fulfilling psychological needs and desires, it is worth noting that all the constructs were measured via self-

259 report in a relatively homogenous sample of Caucasian undergraduate students. Hence, the use of

260 alternative markers and samples is recommended. In addition, the analysis we employed cannot

261 provide information on the causal direction of relationships, particular at the individual difference

262 level where alternative trait variables may explain the relationships. Potential moderators of the

263 relationships examined in this study could also be scrutinized to help facilitate understanding of

264 why some of the relationships found varied across participants. Notwithstanding these limitations,

265 however, the study offers new insights into the varying potential consequences of fulfilling

266 psychological needs advocated within the SDT framework and acquisitive desires. In particular,

267 disentangling within-person and individual difference relationships seems to help distinguish

268 between needs and desires and their impact upon well-being and affective ill-being, but not

269 somatic ill-being. 


\section{References}

275 Bandura, A. \& Locke, E. (2003). Negative self-efficacy and goal effects revisited. Journal of Applied Psychology, 88, 87-99. doi:10.1037/0021-9010.88.1.87

277 Bartholomew, K., Ntoumanis, N., Ryan, R., Bosch, J., \& Thogersen-Ntoumani, C. (2011). Self278 determination theory and diminished functioning: The role of interpersonal control and psychological need thwarting. Personality and Social Psychology Bulletin, 37, 1459-1473. Baumeister, R., \& Leary, M. R. (1995). The need to belong: Desire for interpersonal doi:10.1037//0033-2909.117.3.497

283 Deci, E. L., \& Ryan, R. M. (2000). The "what" and "why" of goal pursuits: Human needs and the 284 self-determination of behavior. Psychological Inquiry, 11, 227-268.

286 doi:10.1207/S15327965PLI1104_01

Hawkley, L., Preacher, K., \& Cacioppo, J. (2011). As we said, loneliness (not living alone) predicts individual differences in sleep quality: A reply. Health Psychology, 30, 136. doi: 10.1037/a0022366 Hogan, R. (1996). A socioanalytic perspective on the five-factor model. In J. S. Wiggins (Ed.), The five-factor model of personality (pp. 163-179). New York: $290 \quad$ Guilford Press.

291 Kanazawa, S. (2003). Can evolutionary psychology explain reproductive behavior in the 292 contemporary United States? Sociological Quarterly, 44, 291-302.

293 Murray, H. A. (1938). Explorations in Personality. New York: Oxford University Press

294 Niemiec, C. P., Ryan, R. M., \& Deci, E. L. (2009). The path taken: Consequences of attaining 295 intrinsic and extrinsic aspirations in post-college life. Journal of Research in Personality, 296 34, 75-91. doi:10.1016/j.jrp.2008.09.001 
297 Rasbash, J., Steele, F., Browne, W. J., \& Goldstein, H. (2009). A user's guide to MLwiN(Version 2.10). Bristol, U.K.: University of Bristol.

Reis, H. T., Sheldon, K. M., Gable, S. L., Roscoe, R., \& Ryan, R. (2000). Daily well-being: The role of autonomy, competence, and relatedness. Personality and Social Psychology Bulletin, 26, 419-435. doi:10.1177/0146167200266002

Ross, S., Cleland, J. A., \& MacLeod, M. J. (2006). Stress, debt and undergraduate medical student performance. Medical Education, 40, 84-589. doi: 10.1111/j.1365-2929.2006.02448.x

Ryan, R. M. \& Frederick, C. M. (1997). On energy, personality, and health: Subjective vitality as a dynamic reflection of well-being. Journal of Personality, 65, 529-565. doi:10.1111/j.1467-6494.1997.tb00326.x

Schat, A., Kelloway, E. K., \& Desmarais, S. (2005). The Physical Health Questionnaire (PHQ): Construct validation of a self-report scale of somatic symptoms. Journal of Occupational

Vansteenkiste, M., Niemiec, C. P., \& Soenens, B. (2010). The development of the five miniHealth Psychology, 10, 363-381. doi:10.1037/1076-8998.10.4.363

Sheldon, K. M., Elliot, A. J., Kim, Y., \& Kasser, T. (2001). What is satisfying about satisfying events? Testing 10 candidate psychological needs. Journal of Personality and Social Psychology, 80, 325-339. doi:10.1037//0022-3514.80.2.325 theories of self-determination theory: An historical overview, emerging trends, and future directions. In T. Urdan \& S. Karabenick (Eds.), Advances in Motivation and Achievement,

317 Watson, D., Clark, L., \& Tellegen, A. (1988). Development and validation of brief measures of positive and negative affect: The PANAS scales. Journal of Personality and Social Psychology, 54, 1063-1070. doi:10.1037//0022-3514.54.6.1063 
